\title{
Pain Management and Symptom-Oriented Drug Therapy in Palliative Care
}

\author{
Carsten Klein Ute Lang Johannes Bükki Reinhard Sittl Christoph Ostgathe \\ Division of Palliative Medicine, University of Erlangen, Germany
}

\author{
Keywords \\ Palliative care - Symptoms - Pain therapy - End of life . \\ Opioids
}

\section{Summary}

Patients with advanced life-limiting disease often suffer from symptoms that considerably impair their quality of life and that of their families. Palliative care aims to alleviate these symptoms by a multidimensional approach. Pharmacotherapy is an essential component. The objective of this review is to give an overview of symptomoriented drug therapy for the most important symptoms in palliative care. Leading symptoms that affect quality of life include pain, dyspnea, nausea and emesis, weakness and disorientation. Careful examination and history taking help to understand the individual mechanisms underlying these symptoms. Specific pharmacotherapy provides an efficient way to achieve symptom control in the context of palliative care.

\section{Introduction}

Physical symptoms can lead to a significant impairment of a patient's quality of life, especially in the late stages of advanced disease. In a curative context improvement of symptoms may indicate a recovery from the illness. Increasing symptom burden in an incurable condition is often the visible and perceptible correlate of progressive disease. The concept of palliative care is to equally address physical complaints as well as psychological, social, and spiritual issues. Patients in a

\author{
Schlüsselwörter \\ Palliativmedizin - Symptome - Schmerztherapie · \\ Sterben · Opioide
}

\section{Zusammenfassung}

Palliativpatienten und damit auch ihre Angehörigen leiden häufig unter belastenden Symptomen, die nachhaltig die Lebensqualität beeinflussen. Die Palliativmedizin will diese belastenden Symptome mithilfe eines multidisziplinären Ansatzes lindern. Einen wesentlichen Baustein in der symptomorientierten Behandlung stellt die medikamentöse Therapie dar. Ziel des vorliegenden Artikels ist es, einen Überblick über die symptomorientierte Behandlung der wichtigsten Beschwerden im Bereich der Palliativmedizin zu geben. Zu diesen Symptomen gehören Schmerz, Luftnot, Übelkeit und Erbrechen, Schwäche und Verwirrtheit. Exakte Anamneseerhebung und Untersuchung helfen, die individuellen Mechanismen, die den vorliegenden Beschwerden zugrunde liegen, zu verstehen. Dadurch wird eine zielgerichtete medikamentöse Therapie zur Symptomkontrolle ermöglicht. palliative care situation may suffer from many different symptoms like pain, dyspnea, nausea, emesis, weakness, constipation, anxiety, or disorientation [1]. According to the concept of 'total suffering', a holistic view of the existing problems is indispensable for a therapeutic approach. In many patients, successful management of physical symptoms is facilitated by integrating psychological, social, and spiritual support. In this article we focus on the aspects of pharmacotherapy of the most common physical symptoms in palliative care.

\section{KARGER \\ Fax +497614520714 \\ Information@Karger.de}

www.karger.com (c) 2011 S. Karger GmbH, Freibur

1661-3791/11/0061-0027\$38.00/0

Accessible online at:

www.karger.com/brc
Dr. med. Carsten Klein

Division of Palliative Medicine

University of Erlangen

Krankenhausstrasse 12, 91054 Erlangen, Germany

Tel. +49 9131 853406-4, Fax -6

carsten.klein@uk-erlangen.de 


\section{Principles of Pharmacotherapy}

Specifically in palliative care, the basic principles of pharmacotherapy need to be kept in mind. Intervals of administration have to be maintained according to the onset and duration of action of the chosen drugs. To avoid inconsistent effects of analgesic treatment, precise timing of medication is helpful (e.g. 8-16-24 h instead of 'three times a day'). The route of administration should be as simple as possible, e.g. oral medication is to be preferred over parenteral (subcutaneous, s.c. or intravenous, i.v.) application whenever possible. To prevent an increase in suffering, possible side effects of the chosen medication have to be anticipated and treated pre-emptively (e.g. nausea when starting an opioid). Wherever possible, a rescue medication for acute exacerbation of symptoms should be prescribed.

\section{Pain}

\section{The WHO Guidelines and Beyond}

Many patients with advanced disease suffer from pain. For the majority, efficient pain control is feasible by means of pharmacotherapy. The first step to successful treatment is an exact pain diagnosis. Medical history and examination help to

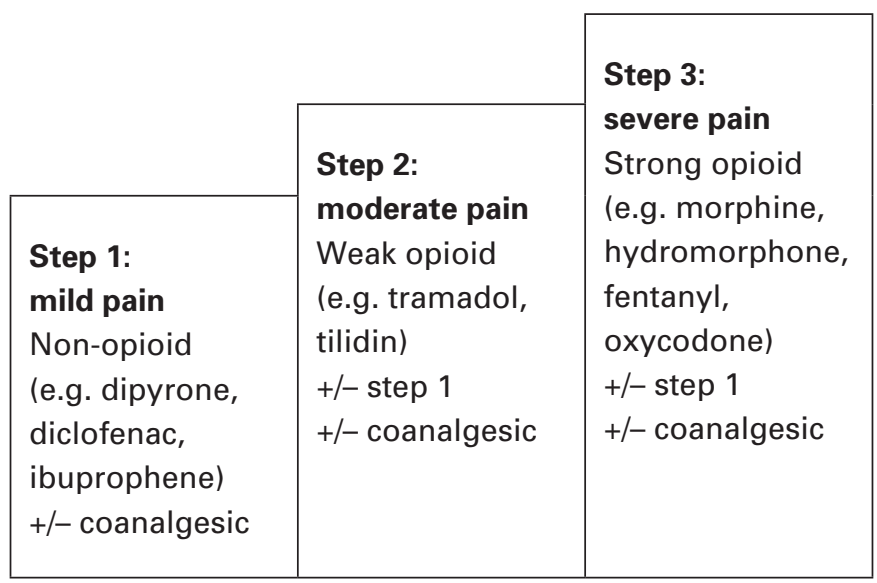

Fig. 1. WHO Ladder of Pain. determine the type of pain (neuropathic, somatic or visceral nociceptive pain, or a combination of these), the location, as well as the pain intensity. The intensity of pain can be easily assessed for example with the verbal rating scale VRS ('no', 'mild', 'moderate', or 'severe pain') or the numeric rating scale $\operatorname{NRS}$ ( 0 = 'no pain', 10 = 'worst pain possible'). Pain diagnosis also has to include factors that affect the intensity of pain (e.g. 'always worse at night', 'when getting up', 'during bowel movement'). It is necessary to ask for such exacerbations and to adjust medication to prevent pain crises through anticipation [2]. The WHO guidelines for cancer pain therapy have been criticized recently for not leading to a mechanism-based access of pain therapy [3]. The approach presented in this article is a first proposal to combine the didactic advantages of a simple scheme [4] and mechanism-based pain therapy.

The type of pain and its assumed pathophysiology enables the treating physician to choose the appropriate pharmacotherapy. According to the WHO guidelines of cancer pain therapy, mild pain can be treated with non-opioids (fig. 1). In the case of musculo-skeletal pain, non-steroidal anti-inflammatory drugs (NSAIDs) can be effective (table 1). The antiinflammatory effect of this substance family is beneficial in painful conditions related to bone metastases, for example. In the case of thrombocytopenia, the risk of bleeding and the benefits of the medication have to be evaluated individually. The risk of bleeding may be lower for Cox-2 inhibitors [5].

Visceral pain is often described as 'squeezing' and is generally difficult to pinpoint. Dipyrone (metamizole) is a good choice because of its additional spasmolytic properties. However, this drug is only available in some countries.

These basic drugs will be of good effect for mild pain. Nevertheless, many patients will need additional analgesia. According to the WHO guidelines for cancer pain relief, moderate pain should be treated with weak opioids, for example tramadol or tilidine. Tilidine is available only in some countries. Codeine is often referred to as an example of weak opioids. Taking into account that its analgesic action depends mostly on the $5-15 \%$ metabolization to morphine, the usage of morphine in corresponding dosages can be discussed.

Patients in severe pain should immediately be treated with strong opioids [6]. The choice of agent, dosage, and route of administration has to meet the patient's needs. In acute pain

Table 1. Examples for non-opioids

$\left.\begin{array}{llllll}\hline \text { Active substance } & \text { Substance class } & \text { Application } & \text { Single dose, mg } & \begin{array}{l}\text { Maximum dose, } \\ \mathrm{mg} / \text { day }\end{array} & \begin{array}{l}\text { Examples for possible } \\ \text { indications }\end{array} \\ \hline \text { Dipyrone (metamizole) } & \text { pyrazolone } & \text { i.v., rect., p.o. } & 500-1,000 & 7,500 & \text { visceral nociceptive pain } \\ \text { Flupirtin } & \text { myotonolytic } & \text { p.o., rect. } & 100-200 & 600 & \text { somatic nociceptive pain } \\ \text { Ibuprofen } & \text { NSAID } & \text { p.o., rect. } & 400-800 & 2,400 \\ \text { Diclofenac } & \text { NSAID } & \text { p.o., rect., i.m., s.c. } & 50-100 \text { p.o./rect. } & 150 \\ \text { Celecoxib } & \text { COX2 inhibitor } & \text { p.o. } & 100-200 & 400 \\ \text { Etoricoxib } & \text { COX2 inhibitor } & \text { p.o. } & 30-120 & 120\end{array}\right\} \begin{aligned} & \text { somatic nociceptive pain, } \\ & \text { especially musculoskeletal pain }\end{aligned}$

s.c. $=$ Subcutaneous; i.v. $=$ intravenous; rect. $=$ rectal; p.o. $=$ oral; i.m. $=$ intramuscular. 
Table 2. Examples for opioids

\begin{tabular}{|c|c|c|c|c|}
\hline Active substance & Application $^{\mathrm{a}}$ & $\begin{array}{l}\text { Analgesic } \\
\text { equivalence }\end{array}$ & $\begin{array}{l}\text { Starting dose for opioid-naive } \\
\text { patients }\end{array}$ & Notes \\
\hline Morphine & p.o., i.v., s.c., rect. & 1 & $\begin{array}{l}2 \mathrm{mg} \text { i.v.; } 5 \mathrm{mg} \text { s.c.; } 10 \mathrm{mg} \text { p.o. } \\
\text { sustained release: } 2 \times 20-2 \times 30 \mathrm{mg}\end{array}$ & $\begin{array}{l}\text { s.c./i.v. to p.o. conversion ratio } 1: 2-1: 3 \\
\text { due to first pass effect }\end{array}$ \\
\hline Buprenorphine & s.l., t.d., i.v. & $60-70$ & $\begin{array}{l}\text { s.1.: } 3(-4) \times 0.2 \mathrm{mg} \\
\text { t.d.: } 35 \mu \mathrm{g} / \mathrm{h}\end{array}$ & see below \\
\hline Fentanyl & t.m., s.c., i.v., t.d. & $70-100$ & $\begin{array}{l}\text { t.d.: } 25 \mu \mathrm{g} / \mathrm{h} \\
\text { t.m.: } 200 \mu \mathrm{g}\end{array}$ & $\begin{array}{l}\text { see below } \\
\text { t.m. not for opioid-naïve patients }\end{array}$ \\
\hline Hydromorphone & p.o., s.c., i.v. & $5-7.5$ & $\begin{array}{l}1.3 \mathrm{mg} \text { p.o.; } 0.5 \mathrm{mg} \text { s.c. } \\
\text { sustained release: } 2 \times 4 \mathrm{mg}\end{array}$ & s.c./i.v. to p.o. conversion ratio $1: 2$ \\
\hline Oxycodone & p.o. & 2 & 10 mg p.o. (only sustained release) & \\
\hline Levomethadone/methadone & p.o. & n.a. & & initiation of therapy only inpatient setting \\
\hline Tramadol & p.o., i.v., s.c., rect. & 0.1 & $\begin{array}{l}50 \mathrm{mg} \text { p.o./s.c. } \\
\text { sustained release: } 2-3 \times 100 \mathrm{mg} \\
10-20 \mathrm{mg} / \mathrm{h} \text { i.v. }\end{array}$ & $\begin{array}{l}\max .600 \mathrm{mg} / 24 \mathrm{~h} \\
\text { risk of serotonin syndrome, } \\
\text { no combination with SSRI }\end{array}$ \\
\hline Tilidine N & p.o. & 0.1 & $\begin{array}{l}50 \mathrm{mg} \text { p.o. } \\
\text { sustained release: } 2-3 \times 100 \mathrm{mg}\end{array}$ & $\begin{array}{l}\max .600 \mathrm{mg} / 24 \mathrm{~h} \text { (tilidine + naloxone; } \\
\text { no parenteral application) }\end{array}$ \\
\hline
\end{tabular}

Table 3. Examples for co-analgesics used in palliative care

\begin{tabular}{|c|c|c|c|}
\hline Co-Analgesic & Starting dose, $\mathrm{mg}$ & $\begin{array}{l}\text { Maximum dose, } \\
\mathrm{mg} / \text { day }\end{array}$ & Notes \\
\hline Carbamazepin & $2 \times 100$ & $800-1,200$ & level monitoring \\
\hline Gabapentin & $3 \times 100$ & $2,400-3,600$ & dose determination within $1-3$ weeks \\
\hline Pregabalin & $2 \times 50-75$ & 300 & $\begin{array}{l}\text { dose determination within 3-4 days, start } \\
\text { at night to minimize sedation effects }\end{array}$ \\
\hline Clonazepam & $3 \times 0.1-0.3$ & $2-4$ & effectiveness can be evaluated after 1 day \\
\hline Amitriptylin & $10-25$ at night & 150 & \\
\hline
\end{tabular}

crises, fast acting formulations should be given, preferably via the parenteral route (i.v., s.c., transbuccal, sublingual, intranasal). As soon as possible, the least aggressive route of application should be used to apply the drug.

Morphine is widely used for cancer pain [7]. Clinical data suggest some advantages of hydromorphone or oxycodone for example concerning side effects $[8,9]$. Yet morphine is still considered as the substance of reference. In the case of renal insufficiency, active metabolites of morphine may accumulate and provoke side effects like sedation or myoclonus. Hydromorphone and oxycodone seem to have no clinically relevant metabolites. The importance of hydromorphone-3-glucoronide is not yet clear [10]. In addition, the lower plasma protein binding of hydromorphone may be favorable. In cases of complex pain and/or opioid tolerance, a trial with levomethadone may be appropriate.

Buprenorphine and fentanyl are available as transdermal therapeutic systems (TTS) (table 2). The slow onset of action has to be taken into account; it may take up to 24-36 h for a TTS to obtain maximum effect [11].

The mu-agonist and norepinephrine reuptake inhibitor tapentadol may be specifically indicated in cases of moderate neuropathic pain due to its dual effect. Up to now, the role of this new central acting analgesic has not yet been defined. The analgesic effect was shown in acute postoperative and chronic non-cancer pain. Results of clinical trials for usage of tapentadol in the context of palliative care are pending.

Titration of strong opioids is limited only by side effects. In the absence of side effects, dosage escalation is possible until sufficient pain relief is achieved. If no satisfactory reduction of pain is achieved by dose escalation or when intolerable side effects occur, opioid rotation may be considered $[12,13]$. The corresponding dosage of different opioids is shown in table 3. When rotating to another opioid, the starting dosage of the new drug should be reduced by $25-50 \%$ due to incomplete tolerance between different opioids. When starting treatment with strong opioids, potential side effects should be explained to the patients. Some of these adverse drug effects persist during opioid application while some are transient. Opioid-induced constipation for example is a persistent phenomenon and has to be treated with obligatory laxatives for the whole period of therapy (e.g. Macrogol 3350 or sodium picosulfate). The opioid antagonist methylnaltrexone can be used as rescue medication in cases of otherwise intractable opioid induced constipation [14]. Fatigue is another commonly complained symptom, but in most patients, duration is limited to 1 week 
or less. Nausea and emesis occur at the beginning of a therapy with opioids with an incidence of $25-35 \%$ and may adversely affect the patient's quality of life [15]. Therefore, parallel to the beginning of treatment with opioids, an antiemetic prophylactic regimen should be started (see below). Usually, the antiemetic drugs can be stopped after 7-10 days. If confusion or persistent fatigue are observed during opioid therapy, the dosage should be reduced or opioid rotation considered.

Sometimes patients as well as professionals are reluctant to start an opioid therapy. There will be no reasons for such concerns if the principles mentioned above are followed. Respiratory depression, for example, does not occur as long as pain reduction guides the dose titration of the opioid. Pain is the physiological antagonist of an opioid-induced respiratory depression. Also in chronic pulmonary disease, pain and dyspnea can be effectively treated by strong opioids.

Strong opioids may also be initiated in the outpatient setting. It is recommended to start with the oral administration of a low dose of a slow-acting opioid (table 2). For on-demand medication, 1/6 (individual variance 1/12-1/3) of the regular daily opioid dose as a solution or rapid releasing tablet should be prescribed. This on-demand medication should be administered in cases of acute pain, with a minimum interval of 45 min between two doses. If the patient requires the additional rapid acting opioid more than 3-5 times a day, the dosage of the slow acting opioid should be increased accordingly. The patient has to be informed that in the case of predictable pain exacerbations, e.g. on movement, this additional medication should be given $30-45$ min prior to the anticipated painful stimulus. Rapid acting fentanyl preparations are an option for on-demand medication in the case of transient severe pain crises (breakthrough pain), while background pain is otherwise generally well-controlled. It has a fast onset of action (between 5 and $15 \mathrm{~min}$ ) and short duration of action. Xerostomia sometimes makes dissolution of the buccal tablets difficult, and some patients dislike the perception of dizziness that is provoked by the rapid absorption of the opioid. In fastacting fentanyl preparations, dose titration should start at the lowest dose; unlike with other opioids, it is not possible to calculate the dose necessary for breakthrough pain control according to the regular opioid daily dose.

Parenteral application of analgesics can be considered, when emesis, mucositis, dysphagia, malabsorption, or reduced consciousness prevents oral application. In the dying patient, when progressive frailty makes swallowing difficult, the subcutaneous route is the application of choice. Compared to intravenous administration, it is less invasive and safer but equally effective [16]. The technique is easy to perform even in an outpatient setting. Butterfly cannulas (25-27 gauge) can be placed into the subcutaneous fatty tissue (preferentially abdomen, thorax, thigh, or upper arm) and fixed with a transparent tape. If no local infection occurs, cannula replacement is recommended just once a week. The opioid can be administered by regular plus on-demand bolus injection or continu- ously with portable infusion systems. After education of the patients and/or relatives, the subcutaneous medication can easily be continued at home.

\section{Neuropathic Pain and Co-Analgesics}

In breast cancer patients, neuropathic pain is a common phenomenon. Causes may be tumoral infiltration of neural structures, metastatic spinal cord compression, as well as therapy-associated neural lesions (radiogenic, cytotoxic). Another cause for neuropathic pain associated with malignancy is post-herpetic neuropathy. Neuropathic pain often is described as burning or 'like an electric shock'. Co-analgesics like antidepressants or antiepileptics are widely used to control neuropathic pain. At the start of the therapy, patients are to be informed that it may take a few days for the drugs to take effect. Dosage should start at a low level for elderly patients or those in poor general condition to minimize side effects like dizziness or sedation.

In cases of moderate to strong pain, opioids have to be added. The effect of opioids alone on neuropathic pain may vary $[17,18]$, a combination with co-analgesics should always be considered. The dosage of strong opioids can be escalated until sufficient alleviation of pain is achieved or side effects limit further increase. Due to its additional NMDA antagonistic effects, methadone and its isomer levomethadone are attributed greater potency in neuropathic pain compared to other opioids [19]. Application is limited by its long plasma half life which can be a cause of cumulation. For that reason, titration of methadone/levomethadone should be performed in an in-patient setting [20]. Invasive non-destructive procedures like epidural application of opioids as well as invasivedestructive procedures are rarely necessary.

\section{Other Co-Analgesics}

Corticosteroids have a negligible primary analgesic effect, but they can be very helpful as co-analgesics. In palliative care situations, they may be used for a variety of indications such as elevated intracranial pressure, nerve, plexus or spinal cord compression, liver capsule pain, tumors in the small pelvis or retroperitoneum, lymphedema, and soft tissue infiltration of the head-neck region as well as peritoneal carcinomatosis. The positive effect is due to the general anti-inflammatory action and the reduction of edema. In addition, corticosteroids have an antiemetic and overall appetite- and moodenhancing effect. With short-term or single-dose use, significant side effects will most probably not occur. High steroid doses may lead to restlessness and anxiety, insomnia, or psychosis. The incidence of general side effects (amongst others thrush and gastric mucosa affection) increases with the duration of application. During steroid therapy, a proton pump inhibitor for gastric ulcer prophylaxis should be applied, in particular if patients are treated with NSAID at the same time. 
Bisphosphonates have become a cornerstone in the management of painful bone metastases. They inhibit the activity of osteoclasts and reduce their number. The painreducing effect is probably achieved through the inhibition of osteolysis and stabilization of the skeleton. The administration of radioactively labeled bisphosphonates (e.g. samarium), can be beneficial even in palliative care situations to reduce cancer bone pain.

Important for pain management are additional non-pharmacological measures: due to the contribution of functional disorders to pain genesis, physical therapy, therapeutic exercises, and occupational therapy have a considerable effect on pain relief. Above all, the preservation of mobility has a positive effect on the quality of life.

\section{Dyspnea}

Dyspnea is a very common and distressing symptom in cancer patients during their last weeks of life [21]. Often, dyspnea is accompanied by anxiety (e.g. due to feeling of suffocation); this dual symptom leads to poor quality of life. Common reasons for dyspnea include pulmonary tumors or metastases, pleural effusions, ascites, anemia, chronic obstructive pulmonary disease, paralysis of the respiratory muscles, pain, pneumonia, and cardiac problems. The most important components of the clinical workup are the physical examination of the patient and a detailed medical history. Ultrasound can easily be used as a bedside technique, e.g. for the diagnosis of pleural effusions. Reversible causes of dyspnea have to be detected and treated, if possible. In many cases, this will not be sufficiently possible, and a rather symptom-oriented approach is appropriate. Symptom-oriented treatment of dyspnea in the context of palliative care focuses on the patient's perception of dyspnea. We know many ways to influence this perception depending on the underlying mechanism. General measures like fresh air, loosening tight clothes, as well as relaxation and breathing exercises may be helpful.

Drug therapy of dyspnea includes the administration of strong opioids, with morphine being the drug of choice. Opioids increase the tolerance towards raised carbon dioxide blood levels in the respiratory centre and reduce the respiratory effort by slowing down the breathing rate [22]. In addition, morphine attenuates - by affecting the limbic system the emotional reaction of the patient to his dyspnea. Opioidnaïve patients receive $5-10 \mathrm{mg}$ fast-acting morphine orally (alternatively $2.5-5 \mathrm{mg}$ s.c. or 1-2 $\mathrm{mg}$ i.v.). The dose is titrated until a significant improvement is achieved or side effects occur. If - after dose titration - dyspnea is controlled, this dose can be converted into a fixed dose of a sustained formulation. In patients who are already treated with opioids the daily dose should be raised by about $50 \%$. Alternatively to morphine, other strong opioids may be used (e.g. hydromorphone). In acute dyspnea combined with anxiety or panic at- tacks, benzodiazepines (e.g. lorazepam 1-2.5 mg sublingually or midazolam 2.5-5 (up to 10) mg slowly i.v./s.c.) or neuroleptics (e.g. promethazine $20-50 \mathrm{mg}$ s.c./i.v.) may be beneficial $[23,24]$. Oxygen which is frequently administered to palliative care patients with dyspnea rarely has an effect on this symptom $[25,26]$. Perception of dyspnea is less often caused by hypoxemia than by the failure of the respiratory apparatus with an increase in breathing effort and an elevated carbon dioxide blood level. The relief some patients describe when they are treated with oxygen is mainly due to trigeminal stimulation. Insufflation of oxygen can also aggravate other symptoms like dry mouth, or it can induce pressure marks on the nose due to the cannula. Only in proven hypoxemia with dyspnea, oxygen is useful as an adjuvant treatment.

Corticosteroids (e.g. dexamethasone orally (p.o.)/s.c./i.v. 8-24 mg/day) can be helpful in dyspnea because of their bronchodilatory, anti-edematous, and anti-inflammatory effects. Particularly in cases of airway obstruction caused by tumor masses, in interstitial malignant disease, as well as in chronic obstructive pulmonary disease, some temporary improvement may be achieved with corticosteroids. Bronchodilatory agents are rarely useful in palliative care. Antibiotics may be effective in patients with pneumonia (e.g. poststenotic) but application should be symptom-oriented [27]. Before invasive procedures (such as paracentesis or drainage of pleural effusions) are performed, a sufficient symptom-oriented drug therapy has to be initiated, in particular in patients with severe dyspnea. In some patients, drainage of pleural effusions or ascites can improve the symptom of dyspnea. However, the sustainability of this effect has to be monitored. From the clinical point of view, the indication for repeated procedures should be questioned if effusions and symptoms recur within less than 7-10 days.

\section{Nausea and Emesis}

The quality of life of many patients in a palliative care situation is negatively affected by distressing symptoms such as nausea and emesis. To date, no straightforward treatment guidelines exist, which would be comparable to the WHO cancer pain guidelines [28]. Antiemetics should be given according to the suspected cause of nausea and vomiting and the target of action. A time schedule according to the duration of pharmacological effect has to be set up, and an on-demand medication should be prescribed additionally. If relief is not achieved, a combination of substances may be necessary. The two (rarely three!) antiemetics should aim at different target sites and mechanisms of action (table 4) to improve efficacy. Levomepromazine (3-6 mg p.o./s.c./i.v.) acts on different receptors and can be referred to as a second-line 'broad-spectrum antiemetic'.

In prophylaxis and therapy of opioid-induced nausea and vomiting, neuroleptic drugs like low-dose haloperidol 
Table 4. Examples for antiemetics

\begin{tabular}{lccll}
\hline Antiemetic drug & $\begin{array}{l}\text { Duration } \\
\text { of action, } \mathrm{h}\end{array}$ & Single dose, $\mathrm{mg}$ & Target site & Indication \\
\hline Cyclizine & 8 & 50 & $\mathrm{~B}$ & $\mathrm{~N} / \mathrm{E}$ caused by obstruction, drug effects, and elevated ICP \\
Dexamethasone & $8-24$ & $4-8$ & multiple & N/E caused by elevated ICP \\
Haloperidol & $8-12$ & $0.3-0.5$ & $\mathrm{C}$ & $\mathrm{N} / \mathrm{E}$ caused by obstruction, drug effects, and elevated ICP \\
Metoclopramide & $4-6$ & 10 & G,C & N/E caused by gastrostasis, drug effects \\
Ondansetron & $8-12$ & $4-8$ & G,C & N/E caused by chemotherapy \\
Levomepromazine & 24 & 6.25 & multiple & N/E caused by obstruction, drug effects, and elevated ICP \\
\hline N/E = Nausea and emesis; ICP = intracranial pressure; $\mathrm{G}=$ gastrointestinal; $\mathrm{C}=$ chemoreceptor trigger zone; $\mathrm{B}=$ vomiting center. \\
\hline
\end{tabular}

(0.3-0.5 mg every $8 \mathrm{~h}$ p.o./s.c.) are agents of first choice. Alternatively, metoclopramide can be effective (10 mg every $4-6 \mathrm{~h}$ p.o./s.c./i.v.).

Certain chemotherapies have a highly emetic potential. Here, prophylactic treatment with 5HT3 antagonists in combination with corticosteroids is effective. In some cases, the substance $\mathrm{P}$ antagonist aprepitant is helpful too [29].

Feeding and food intake has a pronounced social meaning. To prepare a meal for a loved one and/or to support him or her eating can be an intensive expression of love, affection, and care. But in many cases, putting pressure on the patient concerning food intake can aggravate nausea and emesis. If appropriate and according to the patient's wishes, small amounts of (favorite) foods should be offered. Odors as well as sights which trigger nausea and emesis have to be avoided. Artificial nutrition is rarely beneficial for patients in a palliative care situation. In symptom-oriented treatment, the perception of hunger or thirst can be effectively treated by small amounts of food or by moisturizing the oral mucosa, respectively. Fluid intake associated with artificial nutrition may aggravate suffering from hyperhydration. The decision to give or to withhold artificial nutrition is highly emotionally charged and has to be discussed openly with the patient and his family taking into account fears and hopes, benefits and harms [30].

\section{Weakness}

In the terminal phase of progressive disease, the prevalence of weakness is almost $80 \%$. In most of the palliative care patients, it is impossible to identify a precise and treatable cause. Above that, the options for symptom-oriented treatment are limited. Steroids (e.g. dexamethasone $4 \mathrm{mg}$ /day) can have a short-term alleviating effect as described above. Positive effects have been reported for modafinil [31]. Up to now, evidence for that is very limited. The increasing weakness in advanced and progressive illness can be an apparent symptom of the dying process. To communicate this frankly to patients - if possible - and relatives is a principal task of professionals in this phase of the illness. An open and honest communication about the further decrease in vigor allows a shared consideration of the anticipated course of the disease. Often this conversation about weakness can lead to a broader understanding of the disease trajectory.

\section{Disorientation}

Disorientation concerning time, place, person, and/or situation in patients with progressive disease is common. Besides the suffering of the person concerned, the patient's mental impairment is a burden to family and caregivers. In most cases, disorientation is part of a delirious syndrome which depending on the diagnostic criteria used and the underlying disease - is present in up to $40 \%$ of patients on admission to a palliative care service and up to $80 \%$ in the terminal phase. Usually, a delirious syndrome has multiple causes. Drugs, metabolic imbalance, dehydration, hyperhydration, sensory deprivation, infection, advanced age, or structural lesions on the central nervous system may precipitate delirium. Hypercalcemia or hyponatremia should be excluded, and treatable causes like dehydration or adverse effects of opioids approached. Furthermore, the patient's medication should be screened for agents with strong anticholinergic properties (e.g. tricyclic antidepressants), $\mathrm{H}^{2}$ blockers, digitalis, and steroids, which should be discontinued if possible. Even in palliative care settings, approximately half of the delirious syndromes can be temporarily reversed by eliminating or modifying the causes. Sometimes delirium is irreversible and a sign of nearing death. For symptom-oriented drug treatment, neuroleptics, in particular haloperidol $(5-7.5 \mathrm{mg} /$ day; increase dose if needed), often in combination with low-potency and more sedating neuroleptics, e.g. levomepromazine (6.25-12.5 mg/day; increase dose if needed) are favorable.

A possible differential diagnosis that needs to be considered in disoriented patients is a non-convulsive epileptic state, especially in patients with sudden and then fluctuating symptoms [32]. The only method to assure the suspected diagnosis is to perform an electroencephalogram (EEG) which will not be applicable in every clinical situation. In the case of a high suspicion of an epileptic genesis of the disorientation, it can be useful to start anticonvulsive treatment even without diagnostic confirmation. In this case, haloperidol would even be contraindicated as it may lower the epileptic threshold and is 
able to worsen the clinical situation [33]. If antiepileptic treatment is not successful, it should be stopped. Disorientation or delirium should be clearly distinguished from agitation due to symptoms like pain, dyspnea, or anxiety, or due to other neurologic impairments like an aphasic syndrome. If in doubt, empirical treatment of the suspected symptom may be recommended.

\section{Anxiety}

Many seriously ill patients suffer from fears concerning their future, the impending death, and the situation of the ones that will be left behind. This otherwise understandable and appropriate feeling may be very pronounced and distressing in some patients. It may be aggravated by other symptoms like dyspnea or pain, or can in turn be potentiated by other distressing symptoms. Besides supportive and asserting conversations with the patient and his relatives, symptom-oriented drug treatment is often reasonable. The drug of choice in the anxious palliative care patient is lorazepam $(0.5-1-2.5 \mathrm{mg})$ on-demand and/or regularly every $8 \mathrm{~h} \mathrm{[34].} \mathrm{An} \mathrm{alternative}$ drug is midazolam in single doses of $2.5-5-10 \mathrm{mg}$.

\section{Symptom Control During the Last Hours of Life}

The aim of palliative care is to stabilize the physical, psychological, social, and spiritual wellbeing of the patients and their families until death. In the last hours or days of life, all measures including drug treatment have to be revised und focused on the drugs and measures needed to control the symptoms and problems that regularly occur in this period of time (mainly pain, dyspnea, restlessness, and death rattle). It is important to adopt the route of drug administration to the patient's choices and abilities. Some patients will still be able to swallow, but often drug administration has to be changed to a parenteral - preferably the subcutaneous - route.

A common symptom in the dying period is death rattle, a loose upper airway obstruction of sputum and saliva. Because of increasing weakness, many patients are not able to swallow or cough sufficiently anymore. Secretion accumulates in the large airways and induces this noisy breathing. It is generally assumed that patients do not suffer from dyspnea in this situation, but the noisy respiration can be very distressing for relatives and also for team members [35]. Therefore, it is very important to openly communicate about fears and questions, and to support the involved persons as far as possible. A treatment option is scopolamine at a dose of $0.2-0.4 \mathrm{mg}$ s.c. (as required or every $6-8 \mathrm{~h}$ ). Alternatively, atropin or hyoscine butylbromide may be used [36]. The earlier the anticholinergic drug is applied, the better death rattle can be controlled. The more pronounced the symptom is, the more difficult it is to reduce it. Possible side effects are sedation - which may even be desirable - xerostomia, or agitation. Other anticholinergics (butylscopolamine, atropine, or glycopyrrolate) are alternative drugs in the case of death rattle. Clinical experience shows that clearing the mucus by external suction is not beneficial, because this procedure can be more burdensome than the symptom itself and provokes hypersecretion. Dyspnea, pain, and restlessness are to be treated according to the above mentioned principles.

Caring for seriously ill and dying patients is a human and professional challenge for each individual. Many physicians experience their limitations in not being able to stop or even reverse the process. This should not lead to rather invasive or stressing diagnostic or therapeutic measures, if they do not significantly improve the patient's symptom burden. If the drug treatment is appropriate and medical treatment focuses on the multidimensional needs of patients and families, the dying phase may be calm and perceived as peaceful [37].

\section{Disclosure Statement}

Christoph Ostgathe has received lecture fees from the following companies Mundipharma, Cephalon, Nycomed, Grünenthal, Pfizer. Regarding the manuscript, there is no conflict of interest. In the past 3 years, Reinhard Sittl has received lecture fees from Astellas, Grünenthal, Pfizer Inc., and Cephalon. Ute Lang, Johannes Bükki, and Carsten Klein declare that they have no conflicts of interest.

\section{References}

1 Teunissen SC, Wesker W, Kruitwagen C, de Haes HC, Voest EE, de Graeff A: Symptom prevalence in patients with incurable cancer: a systematic review. J Pain Symptom Manage 2007;34:94-104.

2 Zech DF, Grond S, Lynch J, Hertel D, Lehmann KA: Validation of world health organization guidelines for cancer pain relief: a 10-year prospective study. Pain 1995;63:65-76.
3 Raphael J, Ahmedzai S, Hester J, Urch C, Barrie J, Williams J, Farquhar-Smith P, Fallon M, Hoskin P, Robb K, Bennett MI, Haines R, Johnson M, Bhaskar A, Chong S, Duarte R, Sparkes E: Cancer pain: part 1: pathophysiology; oncological, pharmacological, and psychological treatments: a perspective from the British Pain Society endorsed by the UK Association of Palliative Medicine and the Royal College of General Practitioners. Pain Medicine 2010;11:742-764.

4 Mercadante S: Management of cancer pain. Intern Emerg Med 2010;5:31-35.
5 Buvanendran A, Kroin JS, Tuman KJ, Lubenow TR, Elmofty D, Moric M, Rosenberg AG: Effects of perioperative administration of a selective cyclooxygenase 2 inhibitor on pain management and recovery of function after knee replacement a randomized controlled trial. JAMA 2003; 290:2411-2418.

6 Hanks GW, Conno F, Cherny N, Hanna M, Kalso E, McQuay HJ, Mercadante S, Meynadier J, Poulain P, Ripamonti C, Radbruch L, Casas JR, Sawe J, Twycross RG, Ventafridda V: Morphine and alternative opioids in cancer pain: the EAPC recommendations. Br J Cancer 2001;84:587-593. 
7 Nauck F, Ostgathe C, Klaschik E, Bausewein C, Fuchs M, Lindena G, Neuwöhner K, Schulenberg D, Radbruch L: Drugs in palliative care: results from a representative survey in Germany. Palliat Med 2004;18:100-107.

8 Mucci-LoRusso P, Berman BS, Silberstein PT, Citron ML, Bressler L, Weinstein SM, Kaiko RF, Buckley BJ, Reder RF: Controlled-release oxycodone compared with controlled-release morphine in the treatment of cancer pain: a randomized, double-blind, parallel-group study. Eur J Pain 1998;2:239-249.

9 Lussier D, Richarz U, Finco G: Use of hydromorphone, with particular reference to the oros formulation, in the elderly. Drugs Aging 2010; 27:327-335.

10 McCann S, Yaksh TL, von Gunten CF: Correlation between myoclonus and the 3-glucuronide metabolites in patients treated with morphine or hydromorphone: a pilot study. J Opioid Manag 2010;6:87-94.

11 Jeal W, Benfield P: Transdermal fentanyl. a review of its pharmacological properties and therapeutic efficacy in pain control. Drugs 1997;53:109-138.

12 Cherny N, Ripamonti C, Pereira J, Davis C, Fallon M, McQuay H, Mercadante S, Pasternak G, Ventafridda V: Strategies to manage the adverse effects of oral morphine: an evidence-based report J Clin Oncol 2001;19:2542-2554.

13 Fine PG, Portenoy RK: Establishing 'best practices' for opioid rotation: conclusions of an expert panel. J Pain Symptom Manage 2009;38:418-425.

14 Candy B, Jones L, Goodman ML, Drake R, Tookman A: Cochrane database of systematic reviews; in The Cochrane Collaboration, Candy B (eds): Cochrane Database of Systematic Reviews. Chichester, UK, John Wiley and Sons Ltd., 2011.

15 Aparasu R, McCoy RA, Weber C, Mair D, Parasuraman TV: Opioid-induced emesis among hospitalized nonsurgical patients: effect on pain and quality of life. J Pain Symptom Manage 1999;18:280-288.

16 Elsner F, Radbruch L, Loick G, Gärtner J, Sabatowski R: Intravenous versus subcutaneous morphine titration in patients with persisting exacerbation of cancer pain. J Palliat Med 2005;8:743-750.
17 Wu CL, Agarwal S, Tella PK, Klick B, Clark MR, Haythornthwaite JA, Max MB, Raja SN: Morphine versus mexiletine for treatment of postamputation pain: a randomized, placebo-controlled, crossover trial. Anesthesiology 2008;109:289-296.

18 Attal N, Guirimand F, Brasseur L, Gaude V, Chauvin M, Bouhassira D: Effects of iv morphine in central pain: a randomized placebo-controlled study. Neurology 2002;58:554-563.

19 Sotgiu ML, Valente M, Storchi R, Caramenti G, Biella GEM: Cooperative n-methyl-d-aspartate (NMDA) receptor antagonism and mu-opioid receptor agonism mediate the methadone inhibition of the spinal neuron pain-related hyperactivity in a rat model of neuropathic pain. Pharmacol Res 2009;60:284-290.

20 Nauck F, Ostgathe C, Dickerson ED: A German model for methadone conversion. Am J Hosp Palliat Care 2001;18:200-202.

21 Dudgeon DJ, Lertzman M: Dyspnea in the advanced cancer patient. J Pain Symptom Manage 1998;16:212-219.

22 Clemens KE, Klaschik E: Symptomatic therapy of dyspnea with strong opioids and its effect on ventilation in palliative care patients. J Pain Symptom Manage 2007;33:473-481.

23 Nauck F: (Symptom control in the terminal phase). Schmerz (Berlin, Germany) 2001;15:362-369.

24 Clemens K, Klaschik E: Dyspnoea associated with anxiety - symptomatic therapy with opioids in combination with lorazepam and its effect on ventilation in palliative care patients. Support Care Cancer 2010; Epub ahead of print.

25 Clemens KE, Quednau I, Klaschik E: Use of oxygen and opioids in the palliation of dyspnoea in hypoxic and non-hypoxic palliative care patients: a prospective study. Support Care Cancer 2009;17:367-377.

26 Abernethy AP, McDonald CF, Frith PA, Clark K, Herndon JE, Marcello J, Young IH, Bull J, Wilcock A, Booth S, Wheeler JL, Tulsky JA, Crockett AJ, Currow DC: Effect of palliative oxygen versus room air in relief of breathlessness in patients with refractory dyspnoea: a double-blind, randomised controlled trial. Lancet 2010;376:784793.
27 Vitetta L, Kenner D, Sali A: Bacterial infections in terminally ill hospice patients. J Pain Symptom Manage 2000;20:326-334.

28 Harris DG: Nausea and vomiting in advanced cancer. Br Med Bull 2010;96:175-185.

29 Curran MP, Robinson DM: Aprepitant: a review of its use in the prevention of nausea and vomiting. Drugs 2009;69:1853-1878.

30 Palecek EJ, Teno JM, Casarett DJ, Hanson LC, Rhodes RL, Mitchell SL: Comfort feeding only: a proposal to bring clarity to decision-making regarding difficulty with eating for persons with advanced dementia. J Am Geriatr Soc 2010;58:580584.

31 Lundorff LE, Jønsson BH, Sjøgren P: Modafinil for attentional and psychomotor dysfunction in advanced cancer: a double-blind, randomised, cross-over trial. Palliat Med 2009;23:731-738.

32 Lorenzl S, Mayer S, Feddersen B, Jox R, Noachtar S, Borasio GD: Nonconvulsive status epilepticus in palliative care patients. J Pain Symptom Manage 2010;40:460-465.

33 Vella-Brincat J, Macleod AD: Haloperidol in palliative care. Palliat Med 2004;18:195-201.

34 Friedlander MM, Brayman Y, Breitbart WS: Delirium in palliative care. Oncology (Williston Park) 2004;18:1541-1550; discussion 1551-1553.

35 Wee B, Hillier R: Cochrane database of systematic reviews; in The Cochrane Collaboration, Wee B (eds): Cochrane Database of Systematic Reviews. Chichester, UK, John Wiley and Sons Ltd., 2008.

36 Wildiers H, Dhaenekint C, Demeulenaere P, Clement PMJ, Desmet M, Van Nuffelen R, Gielen J, Van Droogenbroeck E, Geurs F, Lobelle J, Menten J: Atropine, hyoscine butylbromide, or scopolamine are equally effective for the treatment of death rattle in terminal care. J Pain Symptom Manage 2009;38:124-133.

37 Radbruch L, Nauck F, Fuchs M, Neuwöhner K, Schulenberg D, Lindena G: What is palliative care in Germany? Results from a representative survey. J Pain Symptom Manage 2002;23:471-483. 